\title{
Dom Paulo Evaristo Arns
}

\section{Luiz Eduardo W. Wanderley ${ }^{I}$}

O LIVRO é uma biografia fecunda da pessoa extraordinária de Dom Paulo Evaristo Arns, cardeal da Igreja Católica, desde 1966, com foco na cidade de São Paulo. Ele, também, é um cidadão proeminente, por sua atuação local, nacional e internacional - foi indicado como cidadão honorário em 38 localidades do Brasil.

São 65 capítulos com contribuições de autores os mais variados, composto de 359 ilustrações, com fotos, trechos de documentos, recortes de jornais e revistas, desenhos, charges e textos singelos e coloquiais.

Um resumo do livro pode ser lido na Apresentação do organizador principal Ricardo Carvalho -, assim expresso:

Em qualquer capítulo você vai encontrar, independente do ano, uma ação de dom Paulo em defesa dos oprimidos e dos Direitos Humanos, contra a censura, a favor da liberdade, incentivando a organização do povo em comunidades, apoiando os movimentos sociais, denunciando a tortura de presos políticos, enfrentando militares - independentemente da patente - oferecendo a Catedral da Sé para missas e cultos ecumênicos.

Suas "vidas" contribuíram, de modo relevante, para a construção da democracia, na cidade paulistana, com irradiações para todo o Brasil e mesmo para o exterior. Uma democracia que abrange as dimensões política, econômica, social, cultural, religiosa.

De sua rica trajetória, ressalto alguns trechos dos autores, que marcaram época em circunstâncias as mais diversificadas.
Revisitando a sua história pessoal, Leonardo Boff cita três paixões que animam a sua vida: a paixão incandescente por Deus, a paixão compassiva pelos pobres na perspectiva de sua libertação, e a paixão lúcida pela inteligência.

Uma das influências que o marcaram foi a teologia da libertação, motivo de resistências dos setores conservadores na sociedade e na própria Igreja institucional, com foco na Cúria Romana. Um trecho do documento enviado a Roma por ele para a Congregação da Doutrina da Fé (leia-se cardeal Ratzinger), diz bem de sua posição: "Na América Latina [...] a libertação é o drama de cada dia, o sangue, a fome, a humilhação e a honra de centenas de milhões de pessoas que lutam para sobreviver por causa do fechamento egoísta ou da indiferença de uma minoria privilegiada aliada às potências deste mundo". Nesse sentido, ele se pronunciou favoravelmente e colocou em prática obras e meios para a libertação dos pobres, pois é a vida de Jesus que conduz a todos aos pobres e à sua libertação. Como é conhecido, por irradiação do Concílio Vaticano II, nas reuniões dos bispos em Medellín e Puebla, no Conselho Episcopal Latino-Americano (Celam), foi acertada a “opção preferencial pelos pobres”. Um exemplo marcante em São Paulo foi a Operação-Periferia e o apelo do cardeal: "A periferia nos pede ação intensa e imediata, e não apenas palavras e bons propósitos". Um objetivo expressivo foi o apoio que Dom Paulo emprestou à Coleção Teologia e Libertação, que contou, na cerrada oposição de setores 


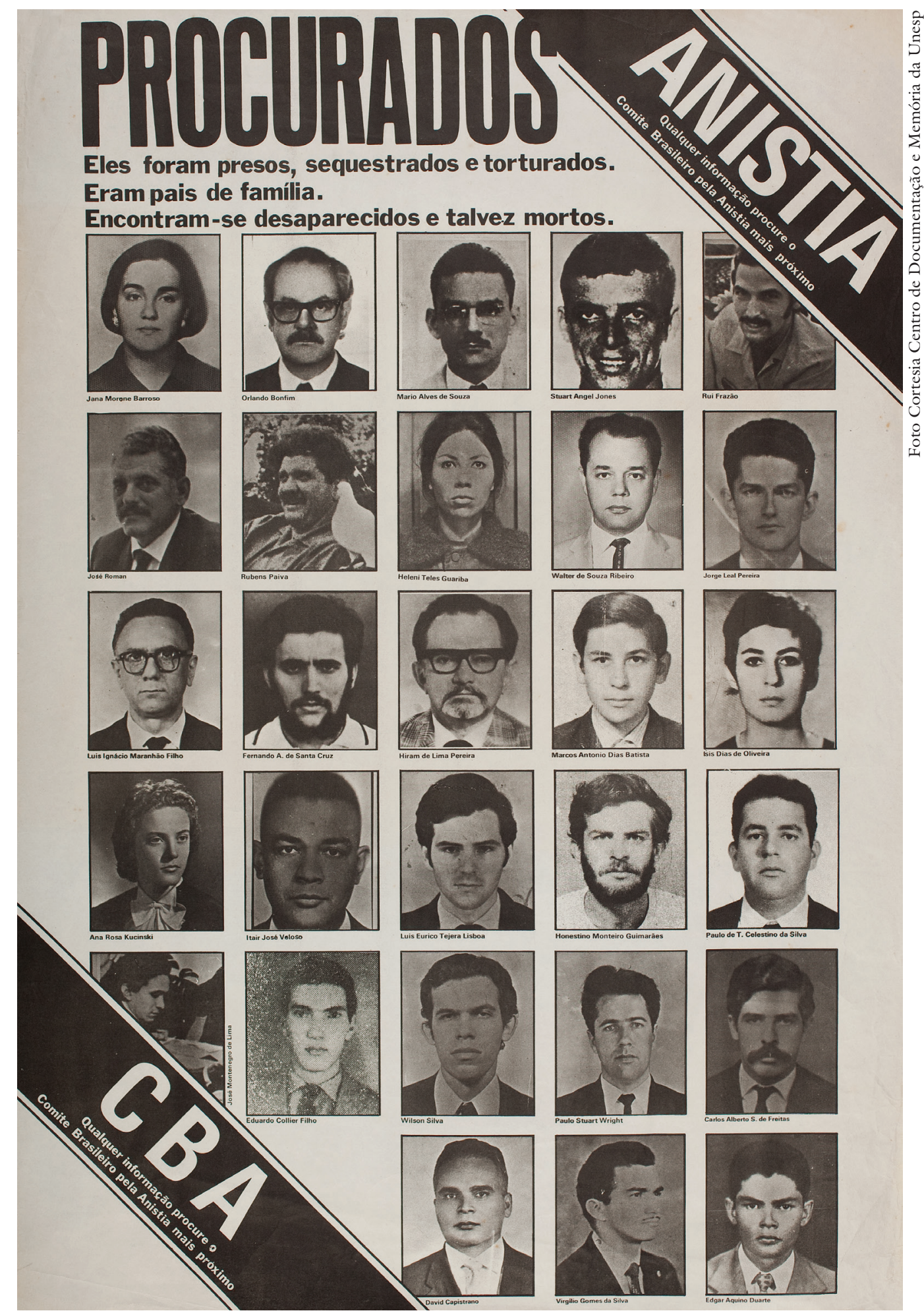

Cartaz do Comitê Brasileiro pela Anistia (CBA) denuncia a prisão, o sequestro e a tortura. 
do Celam e de Roma, com a iniciativa de um Comitê de Patrocínio para o Comitê Editorial, também encabeçado por ele.

Como é conhecido, ele arriscou a própria vida para defender os que o regime julgava "subversivos". Uma contribuição poderosa foi o livro que ele elaborou, com o pastor Wright, intitulado Brasil nunca mais, com relatos de torturas e com sustentação em fontes oficiais dos tribunais militares, corroborando a volta à democracia. Na esfera da defesa dos direitos humanos, ele reagiu contra os opressores - o título do presente livro "O cardeal da resistência" é um mote preciso do que realizou -, com a distribuição de milhares de exemplares da Declaração Universal dos Direitos Humanos, por iniciativa da arquidiocese, bem como em suas conferências sobre essa temática. A repórter Mônica Dallari conseguiu resgatar as 46 fichas do Dops para acompanhar o considerado "subversivo" Dom Paulo. Um dado significativo foi a voz do cardeal no caso de Vladimir Herzog, que os militares anunciaram sua morte como suicídio, e Dom Paulo anunciou que "Herzog foi assassinado" pelo DOI-Codi.

Em 1972, foi criada por ele a Comissão Justiça e Paz de São Paulo, cujo objetivo central era o de anotar os fatos relacionados com as prisões de opositores políticos ao regime, e os fatos eram encaminhados a Dom Paulo que os encaminhava ao conhecimento do general-comandante do II Exército. Considerado como adversário do regime militar, os chefes militares procuraram cercear seus pronunciamentos, fecharam a Rádio 9 de Julho e instalaram a censura na redação do jornal O São Paulo. No seio da própria Igreja houve conflitos entre a Comissão Justiça e Paz de São Paulo

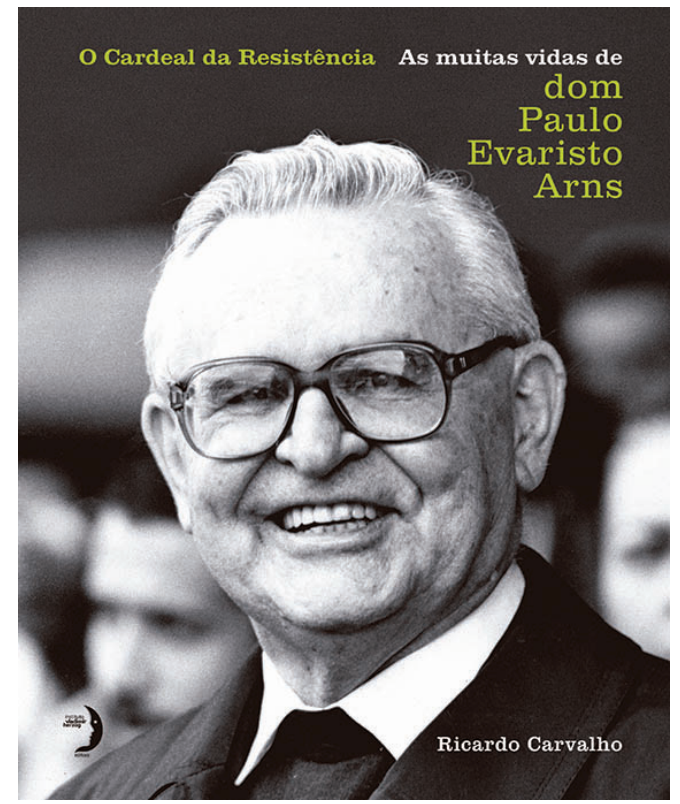

CARVALHO, R. O cardeal da resistência. As muitas vidas de dom Paulo Evaristo Arns. São Paulo:

Editora Vladimir Herzog, 2013.

e a Comissão Nacional de Justiça e Paz, sediada no Rio de Janeiro. Dentre as colocações dos distintos membros da Comissão, demonstrando a participação do cardeal e sua figura enriquecedora, uma frase registrada por José Carlos Dias sintetiza bem como ele era reconhecido: "[...] Dom Paulo terá sido das figuras humanas mais impressionantes que tive a graça de conhecer [...] Sua simpatia pessoal, seu sorriso amigo, seu olhar implacável, emolduram da figura de santidade que gravo no coração".

Um ponto relevante foi a sua valorização do trabalho das mulheres. Um fato estimulante, registrado por Margarida Genevois, que chegou a ser presidente da Comissão Justiça e Paz, foi ela ser nomeada representante do cardeal num congresso ecumênico em Moscou, o que 
ocasionou um espanto enorme nos participantes. Em suas memórias, o cardeal demonstra que procurou reunir as religiosas de todas as congregações, formou mais de uma dezena de grupos dirigidos por lideranças religiosas, analisou o decreto da consagração da mulher à Igreja (aquelas que não entraram na vida religiosa), e proclama que os bispos e padres poderiam contar, então, “[...] com as inspirações e a ajuda constante do gênio feminino, tão necessário para entender muitas passagens da Bíblia e muitíssimas situações da história da humanidade"; num de seus trechos ele salientou o papel de Maria Madalena, para quem Cristo apareceu, em primeiro lugar, para que ela comunicasse a Pedro a ressurreição.

No caso da PUC São Paulo, comparecem fotos da invasão do campus Monte Alegre pela polícia, o incêndio do Tuca (cuja causa é ignorada até hoje), bem como o evento de doação do título de doutor honoris causa a Dom Helder Câmara, naquele período. Além da minha relação pessoal e institucional com Dom Paulo, e acompanhamento de sua presença em outras conjunturas, em momentos complexos e conflitantes, foi possível constatar sua visão crítica e enriquecedora, que favoreceram a trajetória universitária da Universidade, respeitada sua grande autonomia e liberdade de pensamento, bem como compreensão das suas dificuldades e conquistas reconhecidas em todo o país. Um acontecimento de destaque foi a nomeação de uma reitora, Nadir Kfouri (com duas fotos no livro), a primeira Universidade católica do mundo a indicar uma mulher para esse cargo. A dimensão acadêmica de Dom Paulo pode ser apreciada pelos 24 títulos honoris causa recebidos em universidades do mundo inteiro.
Um tópico relevante da sua caminhada foi a adesão ao ecumenismo, realizado com parcerias em atividades e em atos de participação conjunta na Catedral da Sé. Ecumenismo entendido como respeito às outras religiões e culturas, traduzido no diálogo efetivo inter-religioso.

Nas palavras de Leonardo Boff: "No entardecer da vida, guarda a chama viva da espiritualidade franciscana, simples, despojada e pobre. Alegre e lentamente, vai ao encontro do Senhor a quem sempre serviu especialmente nos outros mais penalizados pela vida e pela sociedade injusta".

Luiz Eduardo W. Wanderley é sociólogo, professor titular do Departamento de Sociologia da PUC-SP, da qual foi reitor (1984-1988). Coordena o Núcleo de Estudos Latino-Americanos (Nelam) do PEPG em Ciências Sociais/PUC-SP.

@ - marilew@uol.com.br

${ }^{\text {I }}$ Departamento de Sociologia, Pontifícia Universidade Católica, São Paulo/SP, Brasil. 